\title{
Innovation and Identity in Distance Language Learning and Teaching
}

\author{
Cynthia White
}

\begin{abstract}
Innovation in distance language learning and teaching has largely focused on developments in technology and the increased opportunities they provide for negotiation and control of learning experiences, for participating in collaborative learning environments and the development of interactive competence in the target language. Much less attention has been paid to pedagogical innovation and still less to how congruence develops between particular pedagogical approaches, various technologies and the skills, practices, actions and identities of language learners and teachers. In this article I explore the process of innovation in distance language teaching from the point of view of key participants in the process, the teachers, and the ways in which their identities are disrupted and challenged as they enter new distance teaching environments. Innovative approaches to distance language teaching are analysed for the insights they provide into the sites of conflict and struggle experienced by teachers, experiences which have a major impact on their selves as distance teachers and on the course of innovation. To conclude I argue that attention to issues of identity can deepen our understanding of innovation, of the tensions that are played out in the experiences and responses of teachers, and of the ways they accept or resist the identity shifts required of them.
\end{abstract}

Key Words:

Distance education, identity, innovation, language teaching

6, 806 words (including references) 


\title{
Innovation and Identity in Distance Language Learning and Teaching
}

\author{
Cynthia White
}

\section{Introduction}

Distance language learning - and language learning in related contexts such as distributed learning, blended learning, and online learning - continues to expand around the world as learners and teachers sense the convenience and potential in new ways of configuring and accessing learning opportunities. Technology has changed our understanding of what it means to teach and learn a language, and teaching roles, in response to these changes, are being altered and transformed. Ongoing innovation has offset one of the most significant limitations of distance language learning, namely the physical separation of teachers and learners, and made possible by a range of technology-mediated ways to develop interactive competence in the target language. Over the past two decades there have been significant shifts in distance language teaching from traditional paradigms focused on independent learning facilitated by self-instructional materials to emerging paradigms focusing on collaborative control of learning experiences (White, 2006a). There are now new learning contexts comprising interconnected communities rather than a series of individual learners; there are new mediums to explore such as task-based CMC, web quests and audiographics; and there are new ways in which learners go about their learning with higher levels of interaction and collaboration with remote participants. These changes require distance language teachers to not only develop new teaching practices in new mediums but to undergo a shift in their identity as language teachers and their understanding of language teaching and learning activities. Parallel changes are required of learners.

Rogers' widely-accepted definition of innovation as ' ....an idea, practice or object that is perceived as new by an individual or other unit of adoption’ (2003:, 12) corresponds with a view of distance education as an innovation for individuals, institutions and the field of language learning and teaching. Critically Rogers notes that an innovation does not have to be 'objectively' new, but rather perceived as new; what is familiar in one context can appear as an innovation in another. Over the past decade attention has been paid to the study of innovation and educational change in language teaching (Carless, 1998; Hall \& Hewings, 2001; Kennedy \& Kennedy, 1996: Markee, 1997) in distance education (see for example Lockwood \& Gooley, 2001) and in distance language teaching (Baumann, 2004), increasing our understanding of how individuals respond to change, and the difficulty of identifying and fostering productive educational change. As Fullan (2001) observes, innovation in educational settings is fraught with unknowns and perhaps all the more so within distance education as many aspects of professional practice remain relatively unknown or little understood.

Uptake of an educational innovation is about personal, pedagogical and institutional change, whether desired or required. In distance education the experience of innovation and change has tended to be explored and articulated more in terms of the external dimensions of change, exploring in detail such aspects as resourcing, 
organizational issues, human resource capacity and the use of technology (Latchem \& Hanna 2001, Robinson 2001). The central purpose of this article is to more fully understand the process of innovation in distance language teaching and learning by exploring the internal dimensions of innovation which are easily overlooked. Here I argue that a fundamental innovative element in distance language learning and teaching is the change within the teachers - in their identity, their understanding of themselves, and what language learning and teaching may now mean in the twenty first century.

\section{Innovation and the Evolution of Distance Language Teaching}

Innovation and the evolution of distance language learning opportunities has largely been in response to the emergence of different generations of technology (see for example Boyle, 1995; Fleming \& Hiple, 2004; Poon, 2003; Wang, 2004; Wang \& Sun, 2001). Successive generations have offered the potential for a progressive increase in learner choice, learner control and opportunities for interaction. In addition they offer a wider range of possibilities for feedback and learner support and also for developing interactive competence. While it has long been acknowledged in distance education that new technologies fundamentally change the instructional paradigm (Bates, 1995), less attention has been given to pedagogical innovation, presenting an incomplete picture of evolving practice. To redress this balance, I identify a key pedagogical innovation associated with each successive generation of distance language teaching.

Wang and Sun (2001) present a four-generational model of distance language teaching, with the first generation comprising print-based correspondence courses, still in use for languages in many parts of the world (Aderinoye, 2005). This traditional paradigm emphasises independent learning facilitated by self-instructional materials with access to support, feedback and, in some cases, some group learning opportunities. An enduring pedagogical innovation associated with this early model is a conversational approach to course development (Holmberg, 1974), combined with an empathetic approach on the part of the teacher to the context and circumstances of each learner (Holmberg, 1995). This approach continues to inform course design with the principle that the 'teaching voice' in the materials should be personalized and empathetic; it also informs the development of teacher-learner relationships where matter-of-fact and programmatic interactions are seen as insufficient for developing adequate social presence, cognitive presence and teaching presence online (Garrison, et al., 2003).

The next generation makes use of broadcast technologies and early forms of multimedia learning. Courses concentrated efforts on improving the quality of students' individual interactions with specially designed printed materials, audio, and videotapes, combined with the use of the telephone. The development of an 'open curriculum' as the core of distance language teaching by Candlin and Byrnes (1995) broke new ground and challenged the traditional dissemination model of distance education. Their radical approach based around Action Projects aimed to encourage learners to move beyond the prescribed subject mater of the course to engage with language resources in their environment; it involved them in making decisions about the content and goals of their learning and provided support through the establishment of learner networks. As a pedagogical innovation based around 'autonomy-enabling features within the curriculum, materials and learning conditions' (Candlin \& Byrnes, 
1995: 9) it represents a fundamental shift in what was considered possible in distance language teaching.

The positioning of distance education as inadequate to meet the interactive requirements of language learning processes began to shift with the advent of CMC (Murray 2000) which was central to the next stage of evolution of distance language teaching. Third generation courses developed asynchronous language learning environments using interactive CD-ROMs, Web presentation of course materials, email and discussion lists. Virtual learning environments were used by some as merely another medium for the transmission of distance learning opportunities associated with first and second generation distance language learning. However it was clear that the new opportunities for communication and interaction changed the relationship between teachers and learners, requiring new roles, new skills and new forms of expertise among teachers. An innovative contribution to pedagogy came from the work of Lamy and Goodfellow (1999a, b) who explored the potential of more fluid course elements (text-based asynchronous conferencing) as a forum for developing reflective processes about the management and sharing of vocabulary learning strategies. The role of the teacher became a focus at this stage too as tutor interactions were examined to identify optimal message types relating to broader issues of online pedagogy, namely reflection on language and learning, and contingent interaction. The study remains an important landmark as an exploration of pedagogical innovation and challenges associated with third generation distance language teaching.

Fourth generation language courses involve interactive synchronous learning opportunities with the instructor and other students as in audiographics, the use of chat lines and oral-visual interaction through Internet-based videoconferencing. By this stage the reach of distance learning experiences had extended significantly with technology-mediated access to authentic encounters with the target language and culture. A noteworthy innovation has come from Tudini (2003) who developed ways of using public native speaker chat rooms as a pedagogical tool for intermediate distance learners of Italian. Tudini's research demonstrates how both technological and pedagogical innovation are required to enable students to interact in dyads with native speakers in a chat program without teacher intervention. Providing distance students with skills to access authentic opportunities to practice and use the target language beyond the distance language course is consistent with the open curriculum referred to earlier and lifelong learning initiatives.

Innovation and the evolution of distance language learning can be seen as a move from a concern with the production and distribution of learning materials, as in broadcast education, to a concern with communication and learning as a social process supported largely by ICT, requiring fundamental shifts in pedagogy, perspectives and practices (White, 2006b). Such innovation goes beyond developing new pedagogical practices; participating teachers find their expectations of life as a language teacher are challenged are confronted with new ways of language learning and teaching. The impact of these aspects of innovation on teachers and teacher identity are explored further in the remainder of the article.

\section{Innovation and Identity}

Studies of teachers taking part in innovative aspects of distance language teaching have focused primarily on the professional challenges and issues they face, alongside changes in their roles and skills. Beginning with issues and challenges, teachers 
entering new teaching environments have been found to focus on structural matters such as technological infrastructure and resourcing (Garing, 2002) and pedagogical issues, such as how to develop and enhance quality teaching-learning relationships in online environments (Ding, 2005; Schramm, 2005). Innovation in distance language teaching has also focused on shifts in teacher roles in online teaching environments (Hauck \& Haezewindt, 1999; Hauck \& Hampel, 2005) and on the new skills teachers need for online distance language teaching. Hampel and Stickler (2005), for example, propose a pyramid of seven categories of skills for teaching languages online beginning with more general skills of working with the technology and its constraints and possibilities, moving on to the social skills of community building, with the highest level comprising skills in teaching languages creatively and developing a personal teaching style online.

The subjective experiences of teachers in the course of innovation, the meanings they assign to those experiences and how they interpret, challenge, resist or reconfigure what may be required of them are not captured in studies focusing on issues, challenges, and changes in roles and skills. Teacher identity has a far greater reach that the notion of teacher role, which is an assigned term reflecting normative approaches to teaching (Britzman, 1992) and more of an outside-in approach to understanding teacher behaviour (White, 2003). Role is concerned with function whereas identity 'voices investments and commitments' and it is the tension between function, what a teacher 'should' do, and investments, or what a teacher feels that makes for the 'lived experience' of teachers (Britzman, 1992: 29). The experience of innovation viewed from the point of view of teachers, how they negotiate their new identities, and how the teacher self is constructed and reconstructed through actions they take in a particular context provides a quite different perspective on the realities and course of innovation in language teaching and of the conflicts, tensions and investments of those intimately involved in the process.

Over the last half century theorists and researchers have tackled the question of the nature of identity from different angles, establishing a range of traditions of identity theory: Eriksonian identity theory (Erikson, 1968; Waterman, 1988), Tajfel's social identity theory (Tajfel, 1978), a socio-cultural approach to identity formation (Penuel \& Wertsch, 1995) and post-structural views of identity (Bhaba, 1987; Britzman, 1993; Foucault, 1983, 1984). More recently teacher identity has been seen as a crucial component in what actually transpires in language teaching and has become a focus in applied linguistics research (see for example Morgan, 2004; Pavlenko 2003). Learner identity has received similar attention (Morita, 2004; Norton, 1997, 2000). In theorizing language teacher identity, Varghese et al. (2005) identify three ideas as central to current understanding of identity - identity is multiple, dynamic and conflictual, it is closely related to social, cultural and political contexts, and is constructed negotiated and maintained to a significant extent through language and discourse. Here I relate each of these aspects to Reynard's (2003) study of an innovative approach to online distance language teaching in which teacher change emerged as crucial to understanding how the new course actually unfolded. The teachers in the study had all worked within a distance language course for adult migrant ESL students described as a linear lock-stepped correspondence program; the new element was the introduction of an alternative online program - labelled the 'dynamic' mode - providing Internet-based open self-selection of all content. Students were free to choose either the linear or dynamic program with the same communication modes available for both, namely e-mail, telephone, chat, and asynchronous discussion boards. 
In Reynard's study the teachers were familiar with the traditional distance program in which students had to complete a unit lesson, including all practice and support sessions before progressing to the next lesson, with the teacher in charge of this progression. In the online mode students could navigate freely the instructional resources and self-select content based on their perceived and identified learning needs. The recentering of control from the teachers to the students in terms of the content, direction and rate of learning, and the ongoing negotiation of learning needs and goals, placed new demands on the teachers, demands which they struggled to adapt to. It conflicted deeply with their established sense of themselves as distance teachers and what could reasonably be required of them. While students clearly preferred the dynamic online mode, teacher resistance to the pedagogical shifts required of them in the new learning environment severely limited what was possible. As the study progressed teachers increasingly disengaged from the more open course format.

Context played a crucial role in teacher identity and the identities available to teachers in the study. The separation of course design and course delivery contexts and functions meant that teachers working with students in the dynamic distance language course format had little experience or investment in the new, alternative course. While teacher education and orientation programs took place before instruction began they did not have the expected result, that teachers would feel competent and comfortable in the online program.

To a significant extent language and discourse contributed to the way in which identity was constructed, maintained and negotiated. In the dynamic mode, lessons were constructed through open dialogue and negotiation between students and teachers, as in Candlin's open curriculum referred to previously, integrating course content with individualised assignments and discussion. While teachers expressed a commitment to the dynamic course mode and understood the need for active participation on their part, they struggled with this throughout the study and their participation did not in any way match the earlier commitment. Teachers found the environment to be 'overwhelming' and their intervention was 'random' and 'ineffective’ (Reynard, 2003: 123).

In the remainder of the article I explore further the way innovation in distance language teaching and learning disrupts and challenges the identities of teachers. I draw on and interpret two studies in distance language teaching which have as part of their focus the response and experience of teachers working for the first time within the new teaching environment. While teacher identity is not an explicit focus of these studies they provide important insights into the sites of conflict and struggle experienced by teachers which had a major impact on their selves as teachers and on the course of innovation. In analysing the issues and conflicts identified by teachers and the lived realities of their experience of innovation I argue that attention to issues of identity can deepen our understanding of innovation, of the tensions that are played out in the experiences and responses of teachers and learners, and of the ways they accept or resist the identity shifts required of them.

\section{The Experience of Innovation in Distance Language Teaching}

In Australia the final decade of the last millennium saw a series of government initiatives and curricular innovations placing new emphasis on language teaching within schools - at least one Language Other than English (LOTE) was to be taught in 
primary schools, and at least two at secondary schools. Ways of meeting these initiatives involved further innovations, particularly in distance language teaching, to fill gaps in both teacher expertise and provide access to foreign language learning opportunities, two of which are now discussed.

Strambi and Bouvet (2003) provide a rich account of developing French and Italian distance language courses in first a traditional format, and shortly thereafter in an ICT-enhanced format within a traditional campus-based tertiary institution. The courses were a response to the demand for foreign language teachers in Australia and the majority of students were 'mature-age women, with numerous work, family and social commitments' (Strambi \& Bouvet, 2003: 81). Sustaining student motivation and providing opportunities for authentic interaction were identified as two key challenges informing course design and the nature of instructor-student interactions. Here I analyse the experience of two discrete groups: the teachers, referred to as instructors, responsible for course delivery and interactions with students in the initial low-tech version of the courses, and the language lecturers who designed and developed the ICT-enhanced language courses using CD-ROM and WebCT.

The pedagogical experience of the instructors delivering the low-tech distance courses for the first time is described as 'very formative', 'challenging' and 'demanding':

Instructors reported having to reassess their teaching practices, partly reinventing themselves as pedagogues, as they became aware that teaching languages at a distance required a completely different instructional stand from classroom-based instruction. (Strambi \& Bouvet, 2003: 82)

The process of 'reassessing' practices and 'reinventing' themselves took place on many levels. First many instructors felt the loss of participant structures and boundaries provided by a physical classroom and scheduled classes. The way the course was configured meant that tutors conducted instruction through individual telephone appointments, which they viewed as particularly demanding and timeconsuming. The one-to-one interactions were perceived as pressuring for themselves and for students, compared to the classroom contexts they were used to where students are often assigned pair or group work. Instructors reflected on the intensity of the one-to-one telephone interactions in comparison to classroom-based participant structures where 'learners can take turns in answering the instructors' questions, or even avoid participation altogether; these options were obviously denied to our students' (Strambi \& Bouvet, 2003: 82). What is evident here is that the established practices of face-to-face language classrooms were well known to the instructors who in classroom contexts had fairly stable expectations of the repertoire of knowledge and skills needed to manage their role with a degree of competence. Their identity as language teachers had been shaped and reinforced through the role of classroom language teacher and the face-to-face interactions that make up these arrangements. Distance language teaching disrupted many of those expectations and established practices and entailed a different process of identity enhancement which, initially at least, they found demanding and in conflict with their personal and professional needs.

A related site of struggle concerned the flexible time and place dimension of distance language teaching. The anywhere/anytime feature clearly placed pressures on instructors, and they felt keenly the impact on their personal lives. Strambi and 
Bouvet report that 'some of the instructors felt that the boundary between their professional and personal lives had weakened, since they often had to disrupt their family routines in order to schedule telephone appointments outside of business hours' (Strambi \& Bouvet, 2003: 82). The sense of disruption of boundaries was compounded as instructors felt they were required to share a great deal of personal information with their students during the one-to-one interactions and tasks, something they felt less than comfortable with.

A further challenge to their professional identity that especially concerned some instructors was the degree and extent of involvement required to ensure that students 'were not overcome by feelings of frustration, isolation and anxiety' (Strambi \& Bouvet, 2003: 82) and that initial levels of motivation were sustained. The cultivation of teaching-learning relationships within distance language teaching is aligned with a strong commitment to developing a palpable sense of belonging for distance students. Teachers can build positive relationships with their distance students via regular, personable and committed interaction - and an empathetic approach referred to earlier, all of which can have a positive effect on study and perseverance. Such a personalised approach, however requires a good deal of effort and resources and instructors in Strambi and Bouvet's study struggled to feel comfortable with this requirement. Morgan and McKenzie (2003) argue that the gap between the extent of commitment and support which distance teachers may recognise as valuable and what they have the time, energy and inclination to provide may be both considerable and a source of discomfort. The sense of conflict experienced by the instructors and the various challenges to their identity have been voices elsewhere in the literature as the dilemma of “Is enough too much?” (Morgan \& McKenzie, 2003). In Strambi and Bouvet's study, while the instructors readily acknowledged the need to establish positive interpersonal relationships, and to engage fully with students, the process of establishing much closer relationships with students than in face-to-face classes was uncomfortable and conflicted with their need for a degree of professional distance.

Strambi and Bouvet also focus on language lecturers who were charged with designing the ICT-based distance courses, and reflect that 'we have come to realize how largely unaware we were initially of the many principles and issues pertaining to development of an instructional environment for distance language education' (Strambi \& Bouvet, 2003: 97). They note that the distance course development was in addition to their regular workload and that lecturers were in relatively small languages departments where time and resources were extremely limited. To develop the courses they were reliant on the University's IT support staff who had little awareness of the pedagogical issues of distance language teaching. The design and development process is described as an 'exciting but at the same time extremely challenging and time-consuming task' (Strambi \& Bouvet, 2003: 95). Strambi and Bouvet (2003) note the prevailing sense of struggle they experienced between their own vision and needs as language teaching professionals in conceptualising and developing an appropriate instructional environment and the interests and focus of the IT specialists. They continue 'as a result the time process was extremely time-consuming, as well as frustrating at times, especially when the original design had to be modified to compensate for technical limitations. The risk of developing technology-driven, rather than pedagogically sound materials, was a constant reality' (Strambi \& Bouvet, 2003: 97). Issues of agency were central to the study too: they emphasise the importance of having their needs as course design professionals heard and met: 'it is imperative that administrators be made aware of the complex issues involved in the design of distance language learning environments and that appropriate resources and support be made 
available' (Strambi \& Bouvet, 2003: 97). Looking ahead, the lecturers expressed concerns that without those extra resources for course revision that they may not be able to meet the requirements of iterative and evaluative instructional design. Strambi and Bouvet (2003: 97) conclude that the experience of innovation in distance language teaching has been positive requiring them 'to reassess radically our teaching practices to suit a new teaching and learning context'.

The introduction of satellite transmitted interactive television (ITV) for distance language teaching in schools in the State of Victoria Australia was a largescale innovation with an estimated, 100,000 students taking part (Evans et al., 2000, 2001). Here I trace briefly the way in which ITV was put into operation in primary school settings - how it evolved and how as an innovation it receded into something far removed from the original conception - and how the course of innovation was inextricably related to opportunities for participation and interaction within the learning environment, with profound effects on the roles and identities of teachers and learners. ITV as an innovation was a response to a shortage in teacher expertise in a LOTE and the transmission of language instruction via satellite to schools became a key means of meeting the new curriculum requirements. The languages in the ITV program were Italian, Indonesian, Mandarin, Japanese, French and German, and broadcasts ran for 30 minutes weekly conducted mostly in the target language. Interaction as a key feature of each live broadcast was sustained by live telephone link, fax or e-mail. Broadcasts were supported by materials distributed to schools, and teachers had the opportunity to give feedback and suggestions to the program makers through evaluations and in-service days. The ITV language programs were designed, developed and broadcast by one group, and teachers then facilitated interaction within their classrooms and provided further practice using supplementary materials. Within this structure teacher voice and agency emerged as key issues in the experience and reality of ITV language teaching and learning.

The interactive elements in the ITV program, as originally conceived were attractive and valued by teachers and learners. The range of interactive opportunities such as on-site interactions in schools during the filming of the program, and the discussion of tasks submitted by participants - were highly motivating for the learners and created a real learning community among the participants. The programs were important as reference points for learners and teachers: the interactional parts of the program allowed the teachers to gain a sense of how learners and teachers in other classrooms were working within the program 'to see how other teachers and children interpreted the lessons and to see from another teacher's viewpoint if they were proceeding appropriately' (Evans et al., 2001: 8). Since many of the participating schools were in isolated rural areas, this sense of being part of a larger learning group was valued and a sense of community developed among teachers in participating schools as each one became familiar with the others who were taking part in the program. Networks were enhanced during the stages when the program makers would shoot scenes at particular schools or within participating communities.

For most primary teachers this was their first experience of language teaching and of teaching via ITV. They reported that they enjoyed developing language skills themselves and gained considerable personal satisfaction from this part of the curriculum, with a number undertaking further study in the language (Evans et al., 2001). However considerable demands were placed on them, most of which were beyond their influence or control, and which many, particularly in isolated areas, were ill-equipped to meet. Working in a synchronous learning environment with limited prior information about program content, the teachers felt a sense of strain if they 
were unable to prepare themselves or their classes adequately. Once the broadcast began they had little ability to control the course of the lesson and on the occasions when the course materials did not match the scheduled program, the teachers were put under extra pressure. An additional difficulty for the primary-level teachers in this study came from competing demands: the languages program was only one of many subjects which they taught within an already crowded curriculum. The range of other roles and responsibilities they had to assume within their everyday classroom contexts meant that they were limited in the time and attention they could devote to developing skills for working within the ITV learning environment. Issues of teacher influence and status are important here too. Since the language programs were part of a synchronous learning environment, the teacher needed to ensure that the weekly timetable allowed the class to be available in a particular room at a particular time. This was not always possible, especially in schools where teachers had little influence or support, and many teachers took to videotaping the programs which increased their sense of control but eliminated many of the interactive opportunities.

Once the program was well underway teachers began to report that the classes were moving too quickly particularly in their demands on vocabulary development and that the learners could not keep up, especially in an immersion context. While teachers were given opportunities to shape the nature of the material broadcast to their classrooms through feedback channels, in practice they appeared to have little influence. The feedback did not impact sufficiently on the producers of the course and teachers reported the ongoing sense of strain and struggle they were experiencing in trying to match the program to the needs of their learners. The gap between the level of the learner proficiency and the demands of the programs continued to widen. Ultimately this meant that learners were less motivated, and less able to sustain participation. When teachers saw little response to their ongoing course evaluation they did not feel part of the evolving learning environment, and increasingly they were less engaged than was ideal. Some teachers took to taping and editing the programs to meet the needs of their students, but this meant that the interactive elements were lost. ITV in those classrooms became a static resource, but one that at least provided the teacher with a greater sense of control.

Many aspects of the ITV program were not maintained as originally conceived: there was a gradual down-scaling of the interactive elements within the language programs, the school location shoots declined, the interactive segments were reduced and eventually tapes of previous programs replaced live presentations. The language programs eventually became a static resource rather than an interactive medium with dramatic effects on the viability of the distance language teaching medium. Evans et al. (2001: 1) note that once the rhetoric and intended use of ITV had become detached from realities within the contexts of use, ITV as a potential innovation for distance language teaching 'gradually sank with hardly a ripple'.

\section{Conclusion}

Innovation can take many and diverse forms in distance language teaching at a time when the affordances of virtual learning opportunities continue to evolve, when teaching roles are becoming 'unbundled and reconfigured' (Natriello, 2005: 1898), and technological and pedagogical goal-posts are continually shifting. As distance language teaching expands, it is imperative for the field to find ways of addressing the philosophical, pedagogical and professional issues that arise in a rapidly changing environment, with teacher identity as a significant factor in each of these domains. It 
is critical that teacher identity is not taken for granted as if it were an inert aspect of teaching contexts and processes, or an outcome of pedagogical skills, training or experience. This article has provided some initial insights into the challenging conditions under which distance language teachers work in new learning environments, engaging their identities in complex and difficult ways. How their identities are disrupted, challenged and reconstructed by innovation in language teaching, and how teacher identities interact with and influence the course of innovation are important avenue for further enquiry in applied linguistics. Developing enquiry based on this point of view extends the ecological perspective on language teaching advocated by Tudor (2001: 9) which does not assume 'that the effects of educational technology can be predicted confidently from the inner logic of the technology alone, as this inner logic inevitably interacts with the perceptions and goals of those involved in using it'. Teachers respond to, alter and recreate innovative environments for language teaching in ways that could not have been predicted at the outset, confirming Fullan's view that innovation is fraught with unknowns, for all participants. Equally, those environments transform the experiences and identities of teachers and, when powerfully combined with a sense of community among distance teachers (Ernest \& Hopkins, 2006), opportunities for peer exchange and peer mentoring (Barker, 2002; Hampel \& Stickler, 2005) and critical reflection on practice (White, 2006c), they extend further our understanding of what language learning and teaching now may mean in the twenty-first century.

\section{References}

Aderinoye, R. (2005). Distance education and languages: evolution and change [Review]. The International Review of Research in Open and Distance Learning 6 (3). http://www.irrodl.org/index.php/irrodl/article/view/269/443.

Barker, P. (2002). On being an online tutor. Innovations in Education and teaching International 39 (1), 14-20.

Bates, A. (1995). Technology, Open Learning and Distance Education. New York: Routledge.

Baumann, U. (2005). Managing change in an academic environment: The German programme at the OUUK. In T. Evans, P. Smith and E. Stacey (eds.), Research in Distance Education 6 (pp. 98-107). Geelong, Australia: Deakin University.

Bhaba, H. (1987). Interrogating identity: The real me. In L. Appignanesi (ed.), Identity (pp. 511). London: Institute of Contemporary Arts.

Boyle, R. (1995). Language teaching at a distance: from the first generation model to the third. System 23 (3), 283-294.

Britzman, D. (1992). The terrible problem of knowing thyself: Toward a poststructural account of teacher identity. Journal of Curriculum Theorizing 9 (3), 23-46.

Candlin, C. and Byrnes, F. (1995). Designing for open language learning - Teaching roles and learning strategies. In S. Gollin (ed.), Language in Distance Education. How Far Can We Go? Proceedings of the NCELTR Conference (pp. 126-141). Sydney: NCELTR.

Carless, D. (1998). A case study of curriculum implementation in Hong Kong. System 26 (3), 353-368.

Ding, A. (2005). Theoretical and practical issues in the promotion of collaborative learner autonomy in a virtual self-access centre. In B. Holmberg, M. Shelley and C. White 
(eds.), Distance Education and Languages: Evolution and Change (pp. 40-54).

Clevedon: Multilingual Matters.

Erikson, E. (1968). Identity: Youth and Crisis. New York: Norton.

Ernest, P. \& J. Hopkins (2006). Coordination and teacher development in an online learning environment. CALICO Journal 23 (3) 551-568.

Evans, T., Stacey, E. and Tregenza, K. (2000). Close encounters in distance education: research issues from case-study research on interactive television in schools. In T. Evans (ed.), Research in Distance Education 5 (pp. 1-11). Geelong, Australia: Deakin University.

Evans, T., Stacey, E. and Tregenza, K. (2001). Interactive television in schools: An Australian study of the tensions of educational technology and change. International Review of Research in Open and Distance Learning 2 (1). http://www.icaap.org/iuicode?149.2.1.6.

Fleming, S. and Hiple, D. (2004). Distance education to distributed learning: Multiple formats and technologies in language instruction, 63-82. CALICO Journal 22 (1), 6382.

Foucault, M. (1983). On the genealogy of ethics: an overview of work in progress. In H. Dreyfus and P. Rabinow (eds.), Michael Foucault: Beyond Structuralism and Hermeneutics (2nd edn.). (pp. 229-252). Chicago: The University of Chicago Press.

Foucault, M. (1984). The subject and power. In B. Wallis (ed.), Art After Postmodernism (pp. 417-432). Boston, MA: David R Godine Publishers.

Fullan, M. (2001). Leading in a Culture of Change. San Francisco: Jossey-Bass.

Garing, P. (2002). Adapting and developing e-learning courses: The challenge of keeping the quality. Conference Proceedings DEANZ April 2002. Evolving e-learning, Wellington, New Zealand.

Garrison, D.R., Archer, W. and Anderson, T. (2003). E-Learning in the 21st Century: A Framework for Research and Practice. London: Routledge/Falmer.

Hall, D. and Hewings, A. (2001). Introduction. In D. Hall and A. Hewings (eds.), Innovation in English Language Teaching: A Reader (pp. 1-5). London: Routledge.

Hampel, R. and Stickler, U. (2005). New skills for new classrooms: training tutors to teach languages online. Computer Assisted Language Learning 18 (4), 311-326.

Hauck, M. and Haezewindt, B. (1999). Adding a new perspective to distance (language) learning and teaching - the tutor's perspective. ReCALL 11 (2), 46-54.

Hauck, M. and Hampel, R. (2005). The challenges of implementing online tuition in distance language courses: task design and tutor role. In Holmberg et al. (ed.), Distance Education and Languages: Evolution and Change (pp. 258-277). Clevedon: Multilingual Matters.

Holmberg, B. (1974). Distance Education: A Short Handbook. Malmö: Hermod.

Holmberg, B. (1995). Theory and Practice of Distance Education. London: Routledge.

Kennedy, C. and Kennedy, J. (1996). Teacher attitudes and change implementation. System 24 (3), 351-360.

Lamy, M.-N. and Goodfellow, R. (1999a). 'Reflective conversation' in the virtual language classroom. Language Learning and Technology 2 (2), 43-61.

Lamy, M.-N. and Goodfellow, R. (1999b). Supporting language students' interactions in webbased conferencing. Computer Assisted Language Learning 12 (5), 457-477.

Latchem, C. and Hanna, D. (2001). Leadership for 21st Century Learning: Global Perspectives From Educational Innovators. London: Kogan Page.

Lockwood, F. and Gooley, A. (eds) (2001). Innovations in Open and Distance Learning. London: Kogan Page. 
Markee, N. (1997). Managing Curricular Innovation. New York: Cambridge University Press.

Morgan, B. (2004). Teacher identity as pedagogy: Toward a field-internal conceptualization in bilingual and second language education. In J. Brutt-Griffler and M. Varghese (eds.), Re-writing Bilingualism and the Bilingual Educator's Knowledge Base (pp. 8096). Clevedon: Multilingual Matters.

Morgan, C. and McKenzie, D. (2003). Is enough too much? The dilemma for online distance learner supporters. International Review of Research in Open and Distance Learning 4 (1). http://www.irrodl.org/content/v4.1/mckenzie_morgan.html.

Morita, N. (2004). Negotiating participation and identity in second language academic communities. TESOL Quarterly 38 (4), 573-603.

Murray, D. (2000). Protean communication: The language of Computer-Mediated Communication. TESOL Quarterly 34 (3), 397-421.

Natriello, G. (2005). Modest changes, revolutionary possibilities: Distance learning and the future of education. Teachers College Record 107 (6), 1885-1904.

Norton, B. (1997). Language, identity, and the ownership of English. TESOL Quarterly 31 (3), 409-429.

Norton, B. (2000). Identity and Language Learning: Gender, Ethnicity, and Educational Change. Essex: Longman.

Pavlenko, A. (2003). "I never knew I was a bilingual": Reimagining teacher identities in TESOL. Journal of Language, Identity, and Education 2 (4), 251-268.

Penuel, W. and Wertsch, J. (1995). Vygotsky and identity formation: A sociocultural approach. Educational Psychologist 30 (2), 83-92.

Poon, A. (2003). A challenge for the developer: issues of interactivity and linguisticcognitive appropriateness in English language learning. Open learning 18 (2), 135153.

Reynard, R. (2003). Internet-based ESL for distance adult students - A framework for dynamic language learning. Canadian Modern Language Review 60 (2), 123-142.

Robinson, B. (2001). Innovation in open and distance learning: some lessons from experience and research. In F. Lockwood and A. Gooley (eds.), Innovation in Open and Distance Learning (pp. 15-26). London: Kogan Page.

Rogers, E.M. (2003). Diffusion of Innovation (5th edn.). New York: Free Press.

Schramm, A. (2005). Making online students connect. In Holmberg et al. (ed.), Distance Education and Languages: Evolution and Change (pp. 230-241). Clevedon: Multilingual Matters.

Strambi, A. and Bouvet, E. (2003). Flexibility and interaction at a distance: A mixed-mode environment for language learning. Language Learning and Technology 7 (3), 81102.

Tajfel, H. (1978). Differentiation Between Social Groups: Studies in the Psychology of Intergroup Relations. London: Academic.

Tudini, V. (2003). Using native speakers in chat. Language Learning and Technology 7 (3), 141-159.

Tudor, I. (2001). The Dynamics of the Language Classroom. Cambridge: Cambridge University Press.

Varghese, M., Morgan, B., Johnston, B. and Johnson, K. (2005). Theorizing language teacher identity: Three perspectives and beyond. Journal of Language, Identity and Education 4 (21-44).

Wang, Y. (2004). Distance language learning: interactivity and fourth-generation Internetbased videoconferencing. CALICO Journal 21 (2), 373-395. 
Wang, Y. and Sun, C. (2001). Internet-based real time language education: Towards a fourth generation distance education. CALICO Journal 18 (3), 539-561.

Waterman, A. (1988). Identity status theory and Erikson's theory: Communalities and differences. Developmental Review 8, 185-208.

White, C. (2003). Language Learning in Distance Education. Cambridge: Cambridge University Press.

White, C. (2005). Towards a learner-based theory of distance language learning: The concept of the learner-context interface. In Holmberg et al. (ed.), Distance Education and Languages: Evolution and Change (pp. 55-71). Clevedon: Multilingual Matters.

White, C. (2006a). Autonomy, independence and control: Mapping the future of distance language learning. In D. Gardner (ed.), Self-access, Distance Learning and Language Advising (pp. 56-71). Dublin: Trinity College.

White, C. (2006b). State of the art review article: The distance learning of foreign languages. Language Teaching Research 39 (4), 247-264.

White, C. (2006c). Technology in language teacher education: understanding the choices and challenges. Keynote address presented at the Regional English Language Centre International Seminar on Teacher Education in Language Teaching, 24-26 April, SEAMEO,Singapore. 


\section{Innovation and identity in distance language learning and teaching}

White, Cynthia

2007

http://hdl.handle.net/10179/9714

22/04/2023 - Downloaded from MASSEY RESEARCH ONLINE 